\title{
Biosynthesis of Unusual Moth Pheromone Components Involves Two Different Pathways in the Navel Orangeworm, Amyelois transitella
}

\author{
Hong-Lei Wang • Cheng-Hua Zhao • Jocelyn G. Millar • \\ Ring T. Cardé • Christer Löfstedt
}

Received: 19 April 2009/Revised: 4 January 2010/Accepted: 12 March 2010/Published online: 15 April 2010

(C) The Author(s) 2010. This article is published with open access at Springerlink.com

\begin{abstract}
The sex pheromone of the navel orangeworm, Amyelois transitella (Walker) (Lepidoptera: Pyralidae), consists of two different types of components, one type including (11Z,13Z)-11,13-hexadecadienal (11Z,13Z-16: Ald) with a terminal functional group containing oxygen, similar to the majority of moth pheromones reported, and another type including the unusual long-chain pentaenes, $(3 Z, 6 Z, 9 Z, 12 Z, 15 Z)-3,6,9,12,15$-tricosapentaene $(3 Z, 6 Z, 9 Z, 12 Z, 15 Z-23: \mathrm{H})$ and $(3 Z, 6 Z, 9 Z, 12 Z, 15 Z)-$ $3,6,9,12,15$-pentacosapentaene $(3 Z, 6 Z, 9 Z, 12 Z, 15 Z-25: \mathrm{H})$. After decapitation of females, the titer of 11Z,13Z-16:Ald in the pheromone gland decreased significantly, whereas the titer of the pentaenes remained unchanged. Injection of a pheromone biosynthesis activating peptide (PBAN) into the abdomens of decapitated females restored the titer of 11Z,13Z-16:Ald and even increased it above that in intact females, whereas the titer of the pentaenes in the pheromone gland was not affected by PBAN injection. In addition to common fatty acids, two likely precursors of 11Z,13Z-16:Ald, i.e., (Z)-11-hexadecenoic and (11Z,13Z)11,13-hexadecadienoic acid, as well as traces of (Z)-6hexadecenoic acid, were found in gland extracts. In addition, pheromone gland lipids contained $(5 Z, 8 Z, 11 Z$,
\end{abstract}

H.-L. Wang $\cdot$ C. Löfstedt $(\bowtie)$

Department of Ecology, Lund University,

22362 Lund, Sweden

e-mail: christer.lofstedt@ekol.lu.se

H.-L. Wang $\cdot$ C.-H. Zhao

State Key Laboratory of Integrated Management of Pest Insects and Rodents, Institute of Zoology,

The Chinese Academy of Sciences,

Beijing 100101, China

J. G. Millar • R. T. Cardé

Department of Entomology, University of California,

Riverside, CA 92521, USA
14Z,17Z)-5,8,11,14,17-icosapentaenoic acid, which also was found in extracts of the rest of the abdomen. Deuteriumlabeled fatty acids, $\left(16,16,16-\mathrm{D}_{3}\right)$-hexadecanoic acid and $(Z)$ $\left[13,13,14,14,15,15,16,16,16-D_{9}\right]-11$-hexadecenoic acid, were incorporated into 11Z,13Z-16:Ald after topical application to the sex pheromone gland coupled with abdominal injection of PBAN. Deuterium label was incorporated into the $C_{23}$ and $C_{25}$ pentaenes after injection of $(9 Z, 12 Z, 15 Z)$ $\left[17,17,18,18,18-D_{5}\right]-9,12,15$-octadecatrienoic acid into $1-$ $2 \mathrm{~d}$ old female pupae. These labeling results, in conjunction with the composition of fatty acid intermediates found in pheromone gland extracts, support different pathways leading to the two pheromone components. 11Z,13Z-16: Ald is probably produced in the pheromone gland by $\Delta 11$ desaturation of palmitic acid to 11Z-16:Acid followed by a second desaturation to form 11Z,13Z-16:Acid and subsequent reduction and oxidation. The production of $3 Z, 6 Z, 9 Z$, $12 Z, 15 Z-23: \mathrm{H}$ and $3 Z, 6 Z, 9 Z, 12 Z, 15 Z-25: \mathrm{H}$ may take place outside the pheromone gland, and appears to start from linolenic acid, which is elongated and desaturated to form (5Z,8Z,11Z,14Z,17Z)-5,8,11,14,17-icosapentaenoic acid, followed by two or three further elongation steps and finally reductive decarboxylation.

Key Words Sex pheromone - Biosynthesis ·

Amyelois transitella $\cdot$ Linolenic acid .

(5Z,8Z,11Z,14Z,17Z)-5,8,11,14,17-icosapentaenoic acid ·

$(3 Z, 6 Z, 9 Z, 12 Z, 15 Z)-3,6,9,12,15$-tricosapentaene .

(11Z,13Z)-11,13-hexadecadienal · Bifunctional $\Delta 11$

desaturase · PBAN · Pyralidae

\section{Introduction}

Unsaturated $\mathrm{C}_{10}-\mathrm{C}_{18}$ straight chain alcohols, aldehydes, and acetates have been designated as "Type I" sex 
pheromones of lepidopteran insects, and the majority of the known lepidopteran pheromones fall into this class (Ando et al. 2004). In contrast, a number of species in the families Geometridae, Arctiidae, Lymantriidae, and Noctuidae use polyunsaturated $\mathrm{C}_{17}-\mathrm{C}_{23}$ straight chain hydrocarbons and the corresponding mono- and diepoxide derivatives as pheromone components, classed as "Type II" sex pheromones because of their distinct differences from the Type I group (Millar 2000; Ando et al. 2004).

The Type I alcohol, aldehyde, and acetate components are biosynthesized de novo from fatty acid precursors by a series of desaturation, chain elongation, and chain shortening steps that produce pheromone components with specific chain lengths, double bond positions, and double bond geometries. The structures are completed by the adjustment of the terminal functional group by reduction, oxidation, or tranesterification to provide alcohols, aldehydes, or acetates, respectively (Jurenka and Roelofs 1993; reviewed in Tillman et al. 1999). The evidence to date suggests that all of these transformations are carried out in the pheromone gland.

The biosynthesis of Type II pheromones also has been studied, and from reports of pheromone biosynthesis in the Lymantriidae (Kasang et al. 1979), Arctiidae (Rule and Roelofs 1989), and Geometridae (reviewed in Ando et al. 2008), it is clear that there are significant differences between the biosynthetic pathways leading to the two types of pheromones. These include differences in the biosynthetic sites, the substrates, the enzymes involved, and the endocrine regulation of biosynthesis. In distinct contrast to the site of production of Type I pheromones, it is likely that the polyunsaturated hydrocarbons that constitute Type II pheromones are produced in oenocyte cells by chain extension of diet-derived linoleic or linolenic acids, culminating in reductive decarboxylation to remove the terminal functional group (Rule and Roelofs 1989; reviewed in Ando et al. 2008). The final steps are slightly different for oddvs. even-numbered carbon skeletons. The former probably result from 0-3 cycles of 2-carbon unit chain extension of linoleic or linolenic precursors and subsequent removal of one carbon by reductive decarboxylation to give an oddnumbered chain. In contrast, recent evidence suggests that even-numbered chains probably are produced by the same series of 2 -carbon chain extension steps, then $\alpha$-oxidation and loss of one carbon, followed by loss of a second carbon as $\mathrm{CO}$ or $\mathrm{CO}_{2}$ by an oxidative mechanism (Goller et al. 2007). In some cases, further desaturation also occurs somewhere in the pathway to produce compounds such as the tetraene hydrocarbon pheromones of the arctiid moth Utetheisa ornatrix (Linnaeus) (Choi et al. 2007) and the geometrid moth Operophtera brumata (L.) (Zhao and Löfstedt, unpublished data). The newly formed polyene skeletons then are transported through the hemolymph by lipophorin carriers from the oenocytes to the pheromone gland (Wei et al. 2004; Matsuoka et al. 2006). The polyene hydrocarbons are emitted from the pheromone gland unchanged, or are further transformed by one or more epoxidation steps to produce unsaturated epoxide pheromone components for release (Miyamoto et al. 1999; Jurenka et al. 2003; Wei et al. 2003; Fan et al. 2004; Wei et al. 2004; Matsuoka et al. 2006).

The endocrine regulation of Type II pheromone biosynthesis also is markedly different from that of Type I pheromones. According to studies published to date, pheromone biosynthesis activating neuropeptides (PBANs) are not involved in the production of unsaturated hydrocarbon pheromone components in the arctiid moth $U$. ornatrix (Choi et al. 2007) or the geometrid moth Ascotis selenaria cretacea (Butler) (Wei et al. 2004), but they are involved in the epoxidation of these hydrocarbons in the pheromone gland, for those species that use epoxide pheromones alone or in combination with unsaturated hydrocarbons (e.g., the lymantriid moth Lymantria dispar L. (Jurenka et al. 2003) and the geometrid moth $A$. selenaria cretacea $\mathrm{B}$. (Ando et al. 1997; Wei et al. 2004)).

For many years, it was presumed that a particular lepidopteran species produced either Type I or Type II pheromones, but not both. However, examples of species whose pheromone blends contain compounds of both types recently have been found in two moth families. For example, the pheromone blend of the crambid moth Neoleucinodes elegantalis consists of (E)-11-hexadecen1-ol and (3Z,6Z,9Z)-3,6,9-tricosatriene (3Z,6Z,9Z-23:H) (Cabrera et al. 2001), whereas another crambid species, Deanolis sublimbalis, uses a blend consisting of (Z)-11hexadecenal and 3Z,6Z,9Z-23:H (Gibb et al. 2007). Within the pyralid moth family, several examples are known, including the meal moth, Pyralis farinalis (L.) $[(11 Z, 13 Z)$ 11,13-hexadecadienal (11Z,13Z-16:Ald) (Landolt and Curtis 1982) + 3Z,6Z,9Z,12Z,15Z-23:H; Leal et al. 2005; Kuenen et al. 2010], the navel orangeworm, Amyelois transitella (Walker) [11Z,13Z-16:Ald (Coffelt et al. 1979) + 3Z,6Z, 9Z,12Z,15Z-23:H; Leal et al. 2005; Millar et al. 2005; Kuenen et al. 2010], and the fir coneworm moth, Dioryctria abietivorella (Grote) $[(9 Z, 11 E)-9,11$-tetradecadienyl acetate $(9 Z, 11 E-14: \mathrm{OAc})+3 Z, 6 Z, 9 Z, 12 Z, 15 Z-25: \mathrm{H}$; Millar et al. 2005]. Several other Dioryctria species also appear to have analogous pheromone blends containing both Type I and Type II components (Miller et al., 2010a, b; Löfstedt et al. unpub. data).

The biosynthesis of the blends of Type I and Type II pheromone components in such species has not yet been studied. On the basis of previous pheromone biosynthesis studies, the aldehyde and pentaene pheromone components found in $A$. transitella pheromone glands probably arise from two independent biosynthetic pathways. The conjugated diene aldehyde, 11Z,13Z-16:Ald, may be produced 
from palmitic acid in the pheromone gland, by pathways analogous to those for other conjugated diene Type I pheromones. For example, production of 11Z,13Z-16:Acid, a precursor to the conjugated pheromone in the pine processionary moth, Thaumetopoea pityocampa (Denis and Schiffermüller), involves a bifunctional $\Delta 11$ desaturase (Quero et al. 1997; Abad et al. 2007). By analogy to other systems, it seems likely that the two long-chain pentaenes, $3 Z, 6 Z, 9 Z, 12 Z, 15 Z-23: \mathrm{H}$ and $3 Z, 6 Z, 9 Z, 12 Z, 15 Z-25: \mathrm{H}$, are synthesized in oenocyte cells via chain elongation, desaturation, and decarboxylation of diet-derived linolenic acid or other unsaturated fatty acid precursors, and transported to the gland through the hemolymph (Schal et al. 1998a, b; Jurenka and Subchev 2000; Matsuoka et al. 2006). It also is noteworthy that the above polyenes differ in structure by only one two-carbon unit, suggesting that the polyene motif that is common to both components may be synthesized first, followed by chain length adjustment in the later steps of the biosynthesis.

Thus, the objectives of the work reported here were to study the biosynthesis of the polyene hydrocarbon components and the diene aldehyde pheromone component present in the navel orangeworm pheromone gland, and to gain a better understanding of the mechanisms by which the biosynthesis of these two distinct types of pheromone components are regulated in $A$. transitella, including examining the possible role of PBAN.

\section{Methods and Materials}

Insects The $A$. transitella moths used in this study were obtained from the Department of Entomology, University of California, Riverside, CA, USA. The larvae were fed on a wheat germ diet as previously described (Coffelt et al. 1978; Girling and Cardé 2006), and kept in 4 liter glass jars in controlled environment chambers with 17:7 L:D, 25士 $1^{\circ} \mathrm{C}$ and $65 \%$ relative humidity. Newly emerged adult females were collected daily and held in single-sex cohorts fed with a $10 \%$ honey solution. One- to 2 -d old female pupae and adults were used throughout this study. Pupae were sexed by the morphological differences in their external genitalia.

Chemicals PBAN (Helicoverpa zea pheromone biosynthesis-activating neuropeptide) was purchased from Bachem (Weil am Rhein, Germany). Methyl (9Z,12Z, $15 Z, 18 Z, 21 Z)-9,12,15,18,21$-tetracosapentaenoate and $\left(16,16,16-\mathrm{D}_{3}\right)$-hexadecanoic acid $\left(\mathrm{D}_{3}-16\right.$ :Acid) were purchased from Larodan Fine Chemicals, Malmö, Sweden. The synthesis of $(Z)-\left[13,13,14,14,15,15,16,16,16-D_{9}\right]-11-$ hexadecenoic acid (D9-11Z-16:Acid) was described in Löfstedt et al. (1994), and (9Z,12Z,15Z)-[9,10,12,13,15,16$\left.\mathrm{D}_{6}\right]-9,12,15$-octadecatrienoic acid ( $\mathrm{D}_{6}$-linolenic acid),
(9Z,12Z,15Z)-[17,17,18,18,18-D $]-9,12,15$-octadecatrienoic acid ( $\mathrm{D}_{5}$-linolenic acid), and $(11 Z, 14 Z, 17 Z)-\left[8,8,9,9-\mathrm{D}_{4}\right]-$ icosatrienoic acid $\left(\mathrm{D}_{4}\right.$-icosatrienoic acid) were obtained from R. Adlof as gifts. 3Z,6Z,9Z,12Z,15Z-23:H and 3Z,6Z, 9Z,12Z,15Z-25:H were synthesized as described by Millar et al. (2005), and 11Z,13Z-16:Ald and 11Z,13Z-16:OH were synthesized as described in Kuenen et al. (2010).

$(Z)$ - and $(E)-6-H e x a d e c e n o l(6 Z-16: O H$ and $6 E-16: O H)$ from our laboratory collection of pheromone components were used to prepare the reference standards needed to identify the double bond configuration of methyl 6hexadecenoate in the insect extracts. Thus, $2 \mathrm{mg}$ of $6 Z-16$ : $\mathrm{OH}$ or $6 E-16: \mathrm{OH}$ were dissolved in $1 \mathrm{ml}$ of dimethylformamide (DMF) in a $4 \mathrm{ml}$ screw-cap vial, $100 \mathrm{mg}$ of pyridinium dichromate were added, and the mixture was stirred overnight at room temperature. Then $1 \mathrm{ml}$ of diethyl ether was added, and the mixture was vortexed briefly to precipitate the chromium salts. Distilled water was added, and the ether layer was then collected, washed twice with distilled water to remove traces of DMF, dried over anhydrous sodium sulfate, and evaporated to dryness. Methyl esters were produced by acid-catalyzed esterification $\left(\mathrm{MeOH} / \mathrm{HCl}\right.$ at $80^{\circ} \mathrm{C}$ for $1 \mathrm{~h}$ ).

A reference standard of methyl (11Z,13Z)-11,13hexadecadienoate $(11 Z, 13 Z-16: \mathrm{Me})$ also was prepared from 11Z,13Z-16:Acid by acid-catalyzed esterification.

Extraction of Insect Tissues The pheromone glands of female $A$. transitella, a broad, chevron-shaped structure located on the ventrolateral surface of the intersegmental membrane between abdominal scleromata VIII and IX (Srinivasan et al. 1986), were dissected from cohorts of individual 1 - to 2-d-old intact virgin female moths in both the photophase $(1 \mathrm{~h}$ before lights off) and scotophase $(6 \mathrm{~h}$ after lights off). Each gland was extracted for $30 \mathrm{~min}$ in $10 \mu \mathrm{l}$ of hexane containing $1 \mathrm{ng}$ of $(3 Z, 6 Z, 9 Z)-3,6,9$ henicosatriene $(3 Z, 6 Z, 9 Z-21: \mathrm{H})$ as internal standard. After removing the pheromone glands, the hemolymph, the abdominal cuticle, and the whole abdomen (i.e., cuticle, hemolymph, and abdominal tissues) were extracted separately. For extraction of the hemolymph, ca. $10 \mu \mathrm{l}$ of modified Weever's saline $(21 \mathrm{mM} \mathrm{KCl}, 12 \mathrm{mM} \mathrm{NaCl}, 3 \mathrm{mM} \mathrm{CaCl}$, $18 \mathrm{mM} \mathrm{MgCl}_{2}, 170 \mathrm{mM}$ glucose, $5 \mathrm{mM}$ PIPES, $9 \mathrm{mM}$ $\mathrm{KOH}$, adjusted to $\mathrm{pH}$ 6.6; Carrow et al. 1981) were injected first into the abdomen, and then the mixture of hemolymph and saline was transferred into a glass vial insert by syringe. Methanol (ca. 30-40 $\mu$ l per 3-4 female equivalents of hemolymph) was added, and the mixture was extracted $\times 3$ with $10 \mu \mathrm{l}$ hexane containing $0.1 \mathrm{ng} / \mu \mathrm{l}$ of internal standard (3Z,6Z,9Z-21:H).

The abdominal cuticle was extracted as previously described (Jurenka et al. 2003), first removing the majority of the scales on the abdomen by application of a gentle 
vacuum and then removing the abdomen at the junction of the thorax. The abdomen was cut laterally and pinned open. The ovaries were removed along with the majority of the remaining fat body and organs, leaving mostly epidermal tissue attached to the cuticle. The cuticle was rinsed first with $30 \mu \mathrm{l}$ methanol and then extracted by vortexing $3 \times$ with $100 \mu \mathrm{l}$ hexane containing $0.1 \mathrm{ng} / \mu \mathrm{l} \quad 3 Z, 6 Z, 9 Z-21: \mathrm{H}$ internal standard, $10 \mathrm{~min}$ each time. After extraction, the hexane layers were combined into a new glass tube. The external abdominal cuticle also was extracted in this study by successively dipping five intact female abdomens into $100 \mu \mathrm{l}$ hexane, with $5 \mathrm{sec}$ dipping per individual. The hexane extract then was concentrated to approximately $10 \mu \mathrm{l}$ for GC-MS analysis.

To extract the hydrocarbons from the whole abdomen with only the pheromone gland removed, the abdominal tissues were immersed in $100 \mu \mathrm{l}$ methanol in a $2 \mathrm{ml}$ vial and disrupted with a probe sonicator for a few seconds. The resulting homogenate was extracted by sequential vortexing $3 \times$ with $100 \mu \mathrm{l}$ hexane containing $0.1 \mathrm{ng} / \mu \mathrm{l} 3 Z, 6 Z, 9 Z-21: \mathrm{H}$ internal standard. The hemolymph, cuticle, and abdomen tissue homogenate extracts were dried with anhydrous sodium sulfate and purified by passage through a $7 \times$ $0.2 \mathrm{~cm}$ column of 100-200 mesh Florisil. Approximately $30-40 \mu l$ of a crude hexane extract were added to the column, and hydrocarbons were eluted with $1 \mathrm{ml}$ hexane.

Base Methanolysis and Methylthiolation After the first extraction with hexane, the remaining glandular and abdominal tissues were extracted further for fatty acyl moieties. Thus, the glandular tissue was extracted with $20 \mu \mathrm{l}$ chloroform:methanol $(2: 1 v: v)$ in a glass vial insert for $24 \mathrm{~h}$ at room temperature, then the tissue was removed and the extract was concentrated under a stream of nitrogen. The residue was subjected to base methanolysis to convert fatty acyl moieties to the corresponding methyl esters as described by Bjostad and Roelofs (1984). First, $20 \mu \mathrm{l}$ of $0.5 \mathrm{M} \mathrm{KOH}$ in methanol were added, and the vial insert was placed inside a $4 \mathrm{ml}$ screw-cap vial that was heated for $1 \mathrm{~h}$ at $40^{\circ} \mathrm{C}$. After cooling, $20 \mu \mathrm{l}$ of $0.5 \mathrm{M} \mathrm{HCl}$ in methanol were added to neutralize the alkali, and the mixture was extracted $3 \times$ with $20 \mu$ l hexane. The combined hexane layers were washed twice with $30 \mu \mathrm{l}$ distilled water, then dried over anhydrous sodium sulfate.

The residue from extraction of the abdominal tissue with hexane, in $100 \mu \mathrm{l}$ methanol, was re-extracted with $200 \mu \mathrm{l}$ chloroform for $24 \mathrm{~h}$ at room temperature. The chloroform/ methanol extract was transferred to a new $2 \mathrm{ml}$ vial and concentrated under a stream of nitrogen, then subjected to methanolysis by addition of $200 \mu \mathrm{l}$ of $0.5 \mathrm{M} \mathrm{KOH}$ in methanol and warming to $40^{\circ} \mathrm{C}$ for $1 \mathrm{~h}$. After cooling, $200 \mu \mathrm{l}$ of $0.5 \mathrm{M} \mathrm{HCl}$ in methanol were added, and the mixture was extracted $3 \times$ with $200 \mu$ l hexane, vortexing for
10 min each time. The hexane layers were combined and washed $2 \times$ with $200 \mu \mathrm{l}$ distilled water, and dried over anhydrous sodium sulphate. The resulting solutions of fatty acid methyl esters were analyzed by GC-MS as described below. The double bond positions of monounsaturated methyl esters were determined by GC-MS analysis of their dimethyldisulfide (DMDS) adducts (Buser et al. 1983; Dunkelblum et al. 1985). DMDS derivatizations were carried out by adding $50 \mu \mathrm{l}$ DMDS and $10 \mu \mathrm{l}$ of $5 \%$ (by weight) $I_{2}$ in diethyl ether to $20 \mu 1$ of the solution of methylated fatty acids extracted from the pheromone glands, or $50 \mu \mathrm{l}$ of the methylated fatty acids extracted from the abdomen tissues. Each reaction was stirred in a $2 \mathrm{ml}$ screw-cap vial overnight at $40^{\circ} \mathrm{C}$, then $200 \mu \mathrm{l}$ of hexane were added, and the mixture was washed with $50 \mu \mathrm{l}$ $5 \%$ aqueous sodium thiosulfate. The organic layer then was dried over anhydrous sodium sulfate and evaporated to dryness. The product was taken up in hexane for analysis.

In addition, an extract of artificial diet $(1 \mathrm{~g}$ diet in $1 \mathrm{ml}$ chloroform/methanol for $24 \mathrm{~h}$ ) was used to analyze fatty acids from the diet.

Effect of PBAN on Pheromone Production Unmated female moths (0-24-h-old) were decapitated at the end of the photophase and kept individually in small plastic containers. A piece of wet filter paper was placed inside each container to maintain high humidity so that the decapitated animals would not desiccate. After $24 \mathrm{~h}, 10$ pmol PBAN in $4 \mu \mathrm{l}$ of Weever's saline were injected into the abdomen of each decapitated female. Equal volumes of Weever's saline were injected into decapitated animals as controls. The pheromone glands of treated and control insects were dissected $2 \mathrm{~h}$ later, and each gland was extracted with $10 \mu \mathrm{l}$ hexane containing $0.1 \mathrm{ng}(Z)$-12-tetradecenyl acetate and $0.2 \mathrm{ng}(1,3 Z, 6 Z, 9 Z)-3,6,9$-nonadecatetraene as internal standards.

Labeling Experiment The proposed pheromone precursors, $\mathrm{D}_{3}$-16:Acid, $\mathrm{D}_{9}$-11Z-16:Acid, $\mathrm{D}_{6}$-linolenic acid, $\mathrm{D}_{5}$-linolenic acid, and $\mathrm{D}_{4}-11 Z, 14 Z, 17 Z-20$ :Acid were used to probe the aldehyde and pentaenes biosynthetic pathways. $\mathrm{D}_{3}-16$ :Acid, $\mathrm{D}_{9}$-11Z-16:Acid, and $\mathrm{D}_{6}$-linolenic acid were dissolved in dimethylsulfoxide (DMSO) at a concentration of $12.5 \mu \mathrm{g} / \mu \mathrm{l}$ and topically applied to the extruded pheromone gland ( $0.2 \mu \mathrm{l}$ of DMSO solution; $2.5 \mu \mathrm{g} / \mathrm{gland})$ of PBAN-injected decapitated female adults. $\mathrm{D}_{5}$-linolenic acid and $\mathrm{D}_{4}$ $11 Z, 14 Z, 17 Z-20$ :Acid dissolved in DMSO also were topically applied to pheromone glands of the control group of intact female adults that had not been injected with PBAN. After a $2 \mathrm{~h}$ incubation, pheromone glands were dissected and extracted as described above.

For injection of the possible pheromone precursors, $D_{5^{-}}$ linolenic acid and $\mathrm{D}_{4}-11 Z, 14 Z, 17 Z-20$ :Acid were dissolved 
in vegetable oil $(75 \%$ rapeseed and $25 \%$ sunflower oil, ICA, Sweden.) and injected into the abdomens of 1- to 2-dold female pupae ( $1 \mu \mathrm{l}$ of $100 \mu \mathrm{g} / \mu \mathrm{l}$ solution per female). After adult emergence, at the 6 th $\mathrm{h}$ of the scotophase, the pheromone gland was removed from 2-d-old females and extracted with $10 \mu \mathrm{l}$ hexane containing $0.1 \mathrm{ng} / \mu \mathrm{l} 3 Z, 6 Z$,9Z$21: \mathrm{H}$ as internal standard. After removal of the pheromone gland, the remaining abdominal tissue including the scales was extracted $3 \times$ with $100 \mu \mathrm{l}$ hexane containing $0.1 \mathrm{ng} / \mu \mathrm{l}$ $3 Z, 6 Z, 9 Z-21: \mathrm{H}$ as internal standard as described above. $\mathrm{D}_{4^{-}}$ $11 Z, 14 Z, 17 Z-20$ :Acid dissolved in vegetable oil also was injected into 2-d-old female adults at the $2 \mathrm{nd} \mathrm{h}$ in the scotophase, and the pheromone gland and remaining abdominal tissue were subsequently extracted at the 6th $\mathrm{h}$ in the scotophase, followed by the same protocol.

Coupled Gas Chromatography-Mass Spectrometry The aldehyde and pentaene components in pheromone gland extracts, the corresponding deuterium labeled compounds and precursors, and the fatty acid methyl esters derived from methanolysis of tissue and diet extracts were analyzed with a Hewlett-Packard (Palo Alto CA, USA) 5972 mass selective detector coupled to an HP 5890 series II GC equipped with a capillary column (HP-1MS or InnoWax (SGE, Austin, TX, USA), both $30 \mathrm{~m} \times 0.25 \mathrm{~mm}$ i.d.). The HP-1MS column was programmed from $80^{\circ} \mathrm{C}$ at $10^{\circ} \mathrm{C} / \mathrm{min}$ to $220^{\circ} \mathrm{C}$, hold for $3 \mathrm{~min}$, then to $250^{\circ} \mathrm{C}$ at $4^{\circ} \mathrm{C} / \mathrm{min}$, hold for $5 \mathrm{~min}$, and finally to $280^{\circ} \mathrm{C}$ at $20^{\circ} \mathrm{C} / \mathrm{min}$, hold for $5 \mathrm{~min}$. The InnoWax column was programmed from $80^{\circ} \mathrm{C}$ at $10^{\circ} \mathrm{C} / \mathrm{min}$ to $200^{\circ} \mathrm{C}$, then to $230^{\circ} \mathrm{C}$ at $1{ }^{\circ} \mathrm{C} / \mathrm{min}$, with a final hold for $20 \mathrm{~min}$ at $230^{\circ} \mathrm{C}$.

Selected ion monitoring (SIM) was used to monitor the pheromone compounds and the incorporation of labeled precursors. The following characteristic ions were chosen for the aldehyde and the hydrocarbons: when each of $\mathrm{D}_{3}$ 16:Acid and $D_{9}-11 Z-16$ :Acid was applied, the molecular ion at $\mathrm{m} / \mathrm{z} 236$ was chosen for 11Z,13Z-16:Ald, with $\mathrm{m} / \mathrm{z}$ 239 and 243 being used to monitor the corresponding $D_{3}$ 11Z,13Z-16:Ald and $\mathrm{D}_{7}-11 Z, 13 Z-16$ :Ald, respectively. When $\mathrm{D}_{6}$-linolenic acid was applied to probe the pentaenes biosynthetic pathway, the diagnostic ions at $\mathrm{m} / z 108$ and 178 were used to monitor unlabeled $3 Z, 6 Z, 9 Z, 12 Z, 15 Z-23$ : $\mathrm{H}$, and $\mathrm{m} / z 108$ and 206 were used to monitor unlabeled $3 Z, 6 Z, 9 Z, 12 Z, 15 Z-25: \mathrm{H}$, whereas $\mathrm{m} / z 112(108+4)$ and $\mathrm{m} / \mathrm{z}$ 178 or 206 were used to monitor labeled $3 Z, 6 Z, 9 Z$, $12 Z, 15 Z-23: \mathrm{H}$ or $3 Z, 6 Z, 9 Z, 12 Z, 15 Z-25: \mathrm{H}$, respectively. Specifically, the ions at $m / z 178$ and 206 remain unchanged in the labeled pentaenes because they arise from cleavages from the nondeuterated end of the chains (Millar et al. 2005). When $\mathrm{D}_{5}$-linolenic acid was applied, $m / z 113(108+5)$ and $\mathrm{m} / \mathrm{z} 178$ or 206 were used to monitor labeled $3 Z, 6 Z, 9 Z$, $12 Z, 15 Z-23: \mathrm{H}$ and $3 Z, 6 Z, 9 Z, 12 Z, 15 Z-25: \mathrm{H}$, respectively; and when $\mathrm{D}_{4}-Z 11, Z 14, Z 17-20$ :Acid was used, $m / z 108$ and $m / z 180(178+2)$ were chosen for monitoring labeled $3 Z, 6 Z, 9 Z, 12 Z, 15 Z-23: H$.

\section{Results}

Regulation of Pheromone Production The amount of 11Z,13Z-16:Ald in pheromone gland extracts from decapitated females $24 \mathrm{~h}$ after decapitation and $2 \mathrm{~h}$ after injection of saline was barely detectable $(0.02 \pm 0.02 \mathrm{ng})$ and was significantly lower than the titer in intact control females $(0.25 \pm 0.27 \mathrm{ng}, P=0.016, N=10)$ (Fig. 1). However, $2 \mathrm{~h}$ after injection of PBAN into the abdomens of decapitated females, the pheromone gland titer of 11Z,13Z-16:Ald increased to $1.6 \pm 1.2 \mathrm{ng}(N=9)$, significantly higher than the titer in either decapitated, saline-injected control females $(P<0.001)$ or intact females $(P=0.001)$. By contrast, the titers of $3 Z, 6 Z, 9 Z, 12 Z, 15 Z-23: \mathrm{H}$ and $3 Z, 6 Z, 9 Z, 12 Z, 15 Z-25$ : $\mathrm{H}$ were not affected by PBAN; the levels of each compound found in glands from normal, decapitated PBAN-injected, or decapitated saline-injected control females were not significantly different (Fig. 1).

The two long-chain pentaenes were found in hexane extracts from various tissues including the pheromone gland, the abdominal cuticle, the abdominal tissue, and the hemolymph of 1- to 2-d-old virgin females (Table 1). The titers of each of the two pentaenes in the pheromone gland and abdominal tissue extracts did not differ significantly between the photophase and scotophase (Table 1). There was no evidence for either of the pentaenes on external cuticular surfaces; extracts prepared by quickly dipping intact adult insects in solvent contained no detectable amounts of the pentaenes.

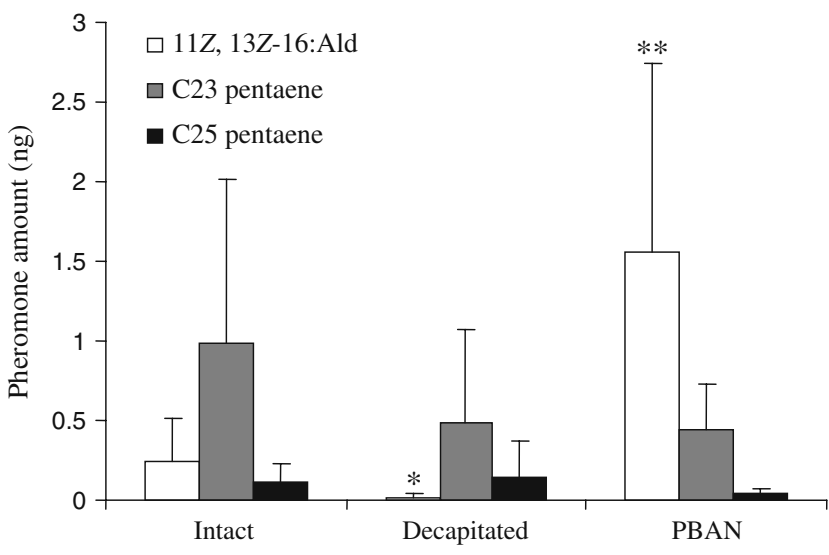

Fig. 1 Titers of 11Z,13Z-16:Ald, 3Z,6Z,9Z,12Z,15Z-23:H, and $3 Z, 6 Z, 9 Z, 12 Z, 15 Z-25: \mathrm{H}$ in pheromone gland extracts from Amyelois transitella intact females, decapitated females injected with saline, and decapitated females injected with 10 pmol PBAN in saline (PBAN). For each column color, significant differences between means were determined by Student's $t$-tests (“*”: $P<0.05$; “**”: $P<0.01$ ) 
Table 1 Titer (ng) of $\mathrm{C}_{23}$ and $\mathrm{C}_{25}$ pentaenes in various tissues of 1-2 day old virgin female navel orangeworm moths ${ }^{\mathrm{a}}$

\begin{tabular}{|c|c|c|c|c|c|c|}
\hline \multirow[t]{3}{*}{ Compound } & \multicolumn{2}{|c|}{ Pheromone Gland } & \multicolumn{2}{|l|}{ Abdomen $^{\mathrm{b}}$} & \multirow{2}{*}{$\frac{\text { Abdominal Cuticle }^{\mathrm{c}}}{(N=7)}$} & \multirow{2}{*}{$\frac{\text { Hemolymph }^{\mathrm{d}}}{(N=2)}$} \\
\hline & \multicolumn{2}{|l|}{$(N=5)$} & \multicolumn{2}{|l|}{$(N=5)$} & & \\
\hline & photophase & scotophase & photophase & scotophase & scotophase & scotophase \\
\hline $3 Z, 6 Z, 9 Z, 12 Z, 15 Z-23: \mathrm{H}$ & $0.40 \pm 0.47$ & $0.45 \pm 0.47$ & $135 \pm 70$ & $111 \pm 39$ & $17 \pm 8$ & $2.9 \pm 0.2$ \\
\hline $3 Z, 6 Z, 9 Z, 12 Z, 15 Z-25: H$ & $0.03 \pm 0.01$ & $0.07 \pm 0.05$ & $10 \pm 6$ & $18 \pm 11$ & $2.0 \pm 1.7$ & $0.71 \pm 0.12$ \\
\hline
\end{tabular}

${ }^{\text {a }}$ Individual 1- to 2-d-old intact virgin female moths (or in the case of hemolymph, samples of four females) were extracted during the last hour of photophase or the $6^{\text {th }}$ hour of scotophase, respectively. The titer of each polyene (mean $\pm \mathrm{SD}$ ) was determined by GC-MS in selected ion monitoring mode using the base peak $(\mathrm{m} / \mathrm{z} 79)$ for quantification versus $3 Z, 6 Z, 9 Z-21: \mathrm{H}$ as internal standard. Student's $t$-tests showed no significant differences at the $5 \%$ level between photophase and scotophase extracted polyenes in the pheromone gland or whole abdominal tissue

${ }^{\mathrm{b}}$ Abdomen $=$ the whole abdomen with the pheromone gland removed, homogenized and extracted

${ }^{\mathrm{c}}$ Abdominal cuticle $=$ the abdominal cuticle with the pheromone gland, hemolymph, fat body, and other tissues removed

${ }^{\mathrm{d}}$ Hemolymph $=$ the mixture of hemolymph and saline extracted from the abdomen, after injection of $10 \mu \mathrm{l}$ Weever's saline per female

Fatty Acid Composition in Abdominal Tissue and Pheromone Gland In addition to saturated and unsaturated fatty acid methyl esters such as methyl tetradecanoate (14:Me, related abbreviations are used hereafter for analogous fatty acid methyl esters), 15:Me, 16:Me, 9Z-16:Me, 17:Me, 18:Me,
9Z-18:Me, 9Z,12Z-18:Me, and 9Z,12Z,15Z-18:Me, the methanolized abdominal tissue and pheromone gland extracts contained the methyl esters of some longer chain saturated and unsaturated fatty acids, including 20:Me, 22: Me, 24:Me, 5Z,8Z,11Z,14Z,17Z-20:Me, as well as traces of
A

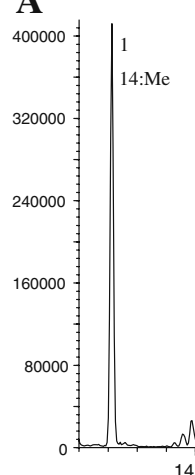

gland
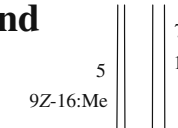
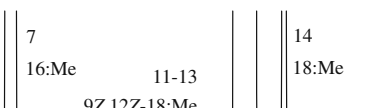
,12Z,15Z-18:Me 9Z-18:Me<smiles>[Li]</smiles>

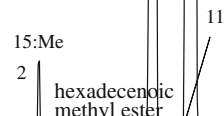
hexadecendic 11Z, 13Z-16:Me methyl ester $17: \mathrm{Me}$ 17:Me $\begin{aligned} & \text { octadecadienoic } \\ & \text { methyl ester }\end{aligned}$ eicosatetratenoic methyl ester (?)
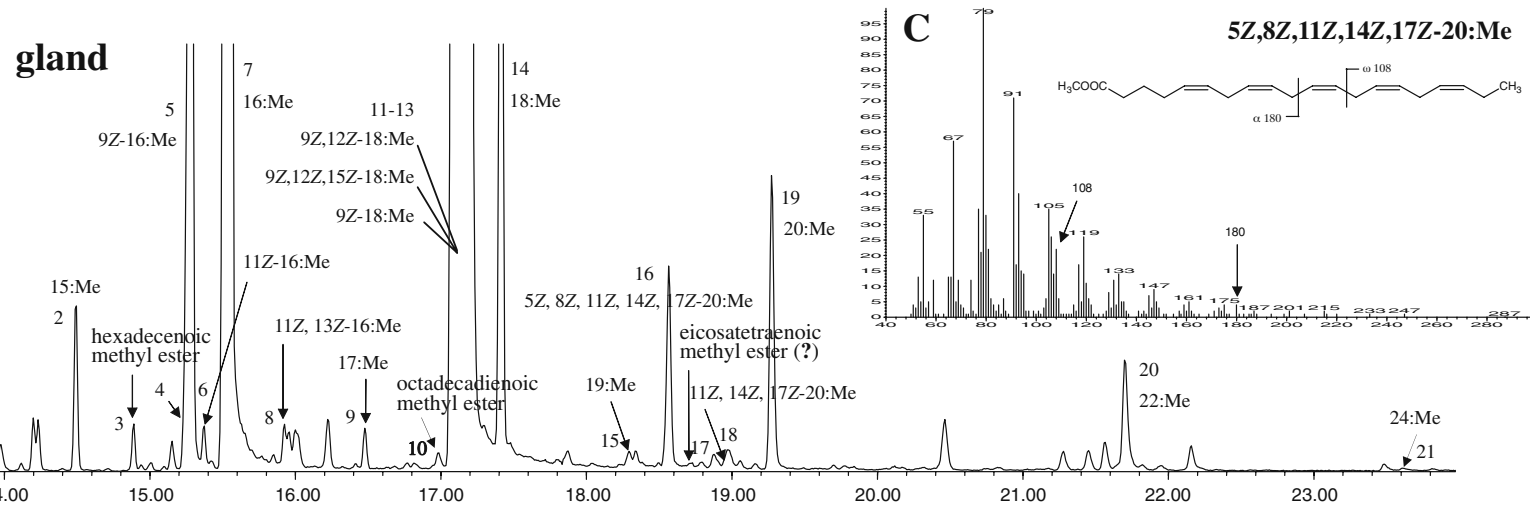

17.00

18.00
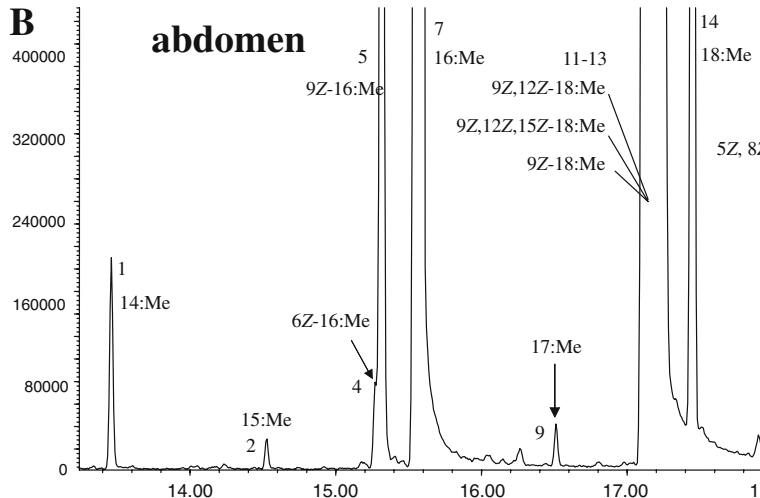

19.00

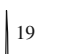

Me

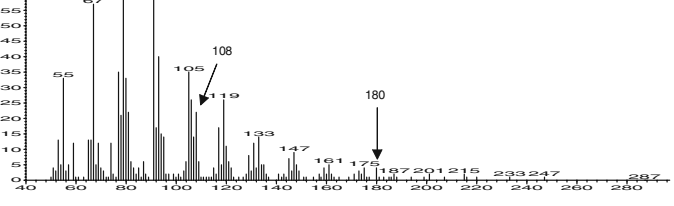

20

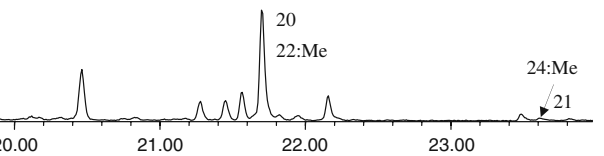

20.00

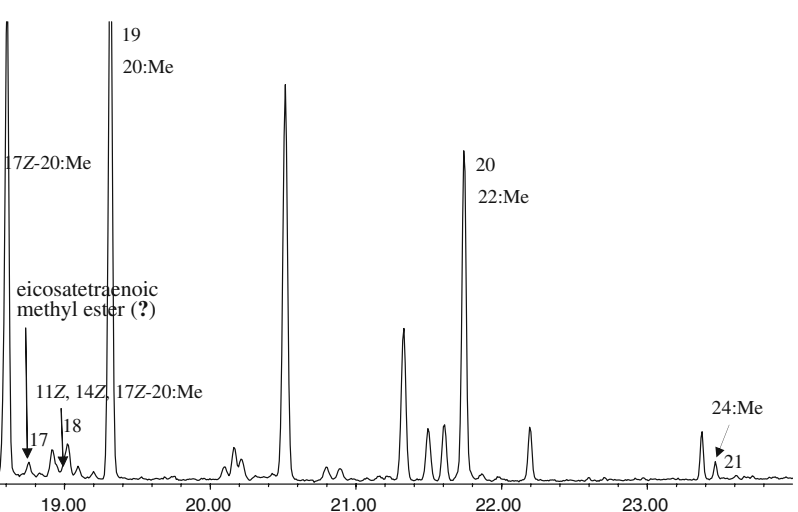

Fig. 2 Total ion chromatograms of the fatty acid compositions (as the methyl esters) of representative pheromone gland (a) and abdominal tissue (b) extracts (HP-1MS capillary column). Fatty acid methyl esters are coded with a number indicating chain length, followed by a number indicating the number of double bonds, with the positions and geometries given if known. Peak numbers correspond to those listed in Table 2. The omega ion at $\mathrm{m} / \mathrm{z} 108$, diagnostic for a 3,6,9-triene

motif, and the alpha ion at $m / z 180$, diagnostic for a 5,8,11-triene motif counting from the other end of the chain are indicated in the mass spectrum of the C20:5 acid methyl ester (c). The weak molecular ion at $\mathrm{m} / \mathrm{z} 316$ was not detected in full scan mode, but it was detected in the more sensitive selected ion monitoring mode, at a same retention time as the two diagnostic ions at $\mathrm{m} / \mathrm{z} 79$ and 108 
two compounds tentatively identified as $11 Z, 14 Z, 17 Z-20$ : $\mathrm{Me}$ and a C20:4 methyl ester (Fig. 2, Table 2). In particular, the mass spectrum of $5 Z, 8 Z, 11 Z, 14 Z, 17 Z-20$ :Me contained diagnostic ions at $\mathrm{m} / \mathrm{z} 108$ and $\mathrm{m} / \mathrm{z} 180$ from the characteristic cleavages and rearrangements of a fatty acid methyl ester with a 5,8,11,14,17 pentaene system (Fellenberg et al. 1987), as well as $m / z 74$ from McLafferty rearrangement of the methyl ester. The molecular ion $(\mathrm{m} / \mathrm{z} 316)$ was not detected in full scan, but it was found in the more sensitive selected ion monitoring mode. Furthermore, this acid must be produced by the insect because it was not found in extracts of the diet used to rear the insects. 11Z,14Z,17Z-20:
Acid also was tentatively identified on the basis of its matching retention time with that of an authentic standard, the characteristic base peak at $\mathrm{m} / \mathrm{z} 79$, and the diagnostic fragment at $\mathrm{m} / \mathrm{z} 108$ from the same cleavage and rearrangement as shown in Fig. 2c for 5Z,8Z,11Z,14Z, 17Z-20:Acid.

In extracts of the pheromone gland, the aldehyde pheromone intermediates 11Z-16:Me and 11Z,13Z-16:Me were found, along with traces of a nonconjugated doubly unsaturated $\mathrm{C}_{18}$ fatty acid that was not completely identified (peak 6, peak 8, peak10, Fig. 2a). These three compounds were not found in the abdominal tissue extracts.

Table 2 Fatty acid methyl esters detected in the pheromone gland and abdomen of female navel orangeworm

\begin{tabular}{|c|c|c|c|c|c|c|}
\hline \multirow[t]{2}{*}{ Compound } & \multirow[t]{2}{*}{ Peak No. ${ }^{a}$} & \multirow{2}{*}{$\begin{array}{l}\text { Pheromone gland } \\
\text { Relative amount }^{\mathrm{b}} \\
(N=7)\end{array}$} & \multirow{2}{*}{$\begin{array}{l}\text { Abdomen }^{\mathrm{c}} \\
\text { Relative amount } \\
(N=6)\end{array}$} & \multicolumn{3}{|c|}{ Criteria used in identifications } \\
\hline & & & & $\mathrm{MS}^{\mathrm{d}}$ & $\begin{array}{l}\text { Retention } \\
\text { time }^{\mathrm{e}}\end{array}$ & $\begin{array}{l}\mathrm{DMDS}^{\mathrm{f}} \\
\text { derivative }\end{array}$ \\
\hline 14:Me & 1 & $12.8 \pm 8.8$ & $2.0 \pm 0.9$ & $\sqrt{ }$ & $\sqrt{ }$ & \\
\hline 15:Me & 2 & $8.2 \pm 5.7$ & $0.20 \pm 0.04$ & $\sqrt{ }$ & $\sqrt{ }$ & \\
\hline Hexadecenoic methyl ester ${ }^{\mathrm{g}}$ & 3 & $2.2 \pm 1.4$ & - & & & \\
\hline $6 Z-16: \mathrm{Me}^{\mathrm{h}}$ & 4 & - & $0.4 \pm 0.2$ & $\sqrt{ }$ & $\sqrt{ }$ & $\sqrt{ }$ \\
\hline $9 Z-16: \mathrm{Me}$ & 5 & $31.8 \pm 12.0$ & $20.1 \pm 7.3$ & $\sqrt{ }$ & $\sqrt{ }$ & $\sqrt{ }$ \\
\hline 11Z-16:Me & 6 & $1.4 \pm 0.8$ & - & $\sqrt{ }$ & $\sqrt{ }$ & $\sqrt{ }$ \\
\hline $16: \mathrm{Me}$ & 7 & 100 & 100 & $\sqrt{ }$ & $\sqrt{ }$ & \\
\hline $11 Z, 13 Z-16: \mathrm{Me}$ & 8 & $1.9 \pm 1.0$ & - & $\sqrt{ }$ & $\sqrt{ }$ & \\
\hline 17:Me & 9 & $1.9 \pm 1.1$ & $0.26 \pm 0.03$ & $\sqrt{ }$ & $\sqrt{ }$ & \\
\hline Octadecadienoic methyl ester ${ }^{\mathrm{g}}$ & 10 & $1.3 \pm 0.8$ & - & & & \\
\hline $9 Z, 12 Z-18: \mathrm{Me}$ & 11 & $33.3 \pm 4.5$ & $38.3 \pm 6.2$ & $\sqrt{ }$ & $\sqrt{ }$ & \\
\hline 9Z,12Z,15Z-18:Me & 12 & $18.5 \pm 4.7$ & $10.7 \pm 2.8$ & $\sqrt{ }$ & $\sqrt{ }$ & \\
\hline 9Z-18:Me & 13 & $90.7 \pm 8.4$ & $76.3 \pm 10.2$ & $\sqrt{ }$ & $\sqrt{ }$ & $\sqrt{ }$ \\
\hline 18:Me & 14 & $21.2 \pm 5.2$ & $10.1 \pm 1.4$ & $\sqrt{ }$ & $\sqrt{ }$ & \\
\hline 19:Me & 15 & $0.8 \pm 0.5$ & $0.14 \pm 0.07$ & $\sqrt{ }$ & $\sqrt{ }$ & \\
\hline $5 Z, 8 Z, 11 Z, 14 Z, 17 Z-20: \mathrm{Me}$ & 16 & $2.5 \pm 0.8$ & $2.0 \pm 0.4$ & $\sqrt{ }$ & $\sqrt{ }$ & \\
\hline eicosatetraenoic methyl ester(?) ${ }^{\mathrm{g}, \mathrm{i}}$ & 17 & $<0.1$ & $0.10 \pm 0.04$ & & & \\
\hline $11 Z, 14 Z, 17 Z-20: \mathrm{Me}^{\mathrm{i}}$ & 18 & $<0.1$ & $<0.1$ & $\sqrt{ }$ & $\sqrt{ }$ & \\
\hline 20:Me & 19 & $3.6 \pm 1.1$ & $2.2 \pm 0.4$ & $\sqrt{ }$ & $\sqrt{ }$ & \\
\hline 22:Me & 20 & $3.1 \pm 2.2$ & $1.6 \pm 0.3$ & $\sqrt{ }$ & $\sqrt{ }$ & \\
\hline 24:Me & 21 & $0.8 \pm 0.5$ & $0.17 \pm 0.14$ & $\sqrt{ }$ & $\sqrt{ }$ & \\
\hline
\end{tabular}

${ }^{\text {a }}$ Numbers refer to gas chromatographic peaks in Fig. 2

${ }^{\mathrm{b}}$ Amounts are reported relative to that of methyl palmitate, the most abundant component

${ }^{\mathrm{c}}$ Abdomen $=$ the whole abdomen with the pheromone gland removed, homogenized and extracted

${ }^{\mathrm{d}}$ Full scan mass spectrum

${ }^{\mathrm{e}}$ Retention time match on both the HP1-MS and InnoWax columns

${ }^{\mathrm{f}}$ DMDS derivative confirmation of double bond location and configuration

${ }^{\mathrm{g}}$ The double bond position was not determined

${ }^{\mathrm{h}}$ 6Z-16:Me in pheromone gland extract was well separated from 9Z-16:Me on the InnoWax column, but the two compounds were not resolved on the HP$1 \mathrm{MS}$ column. However, the same compounds in the abdomen extracts were separated on both columns. The double bond position of 6Z-16:Me was confirmed by DMDS analysis and the configuration was confirmed by comparing the mass spectrum and retention time of both the methyl ester and the corresponding DMDS adduct with those of the reference $6 Z-16$ and $6 E-16$ isomers

${ }^{\mathrm{i}}$ Present in trace amount 
Another unusual monoenoic C16 fatty acid methyl ester was found in the gland and abdomen extracts after DMDS derivatization of the methyl esters fraction. Specifically, a C16 DMDS adduct was found with a molecular ion at $\mathrm{m} / \mathrm{z} 362(6 \%)$ and diagnostic fragment ions at $\mathrm{m} / \mathrm{z} 175$ $(42 \%)$ and $187(81 \%)$, corresponding to the DMDS derivative of $\Delta 6-16$ :Me. By comparing the mass spectrum and gas chromatographic retention times of the methyl ester and its DMDS adduct with those of authentic 6Z-16: $\mathrm{Me}$ and $6 E-16: \mathrm{Me}$ and their DMDS adducts, the natural $\Delta 6-16$ component was shown to be the $6 Z-16: \mathrm{Me}$ isomer (Fig. 3).
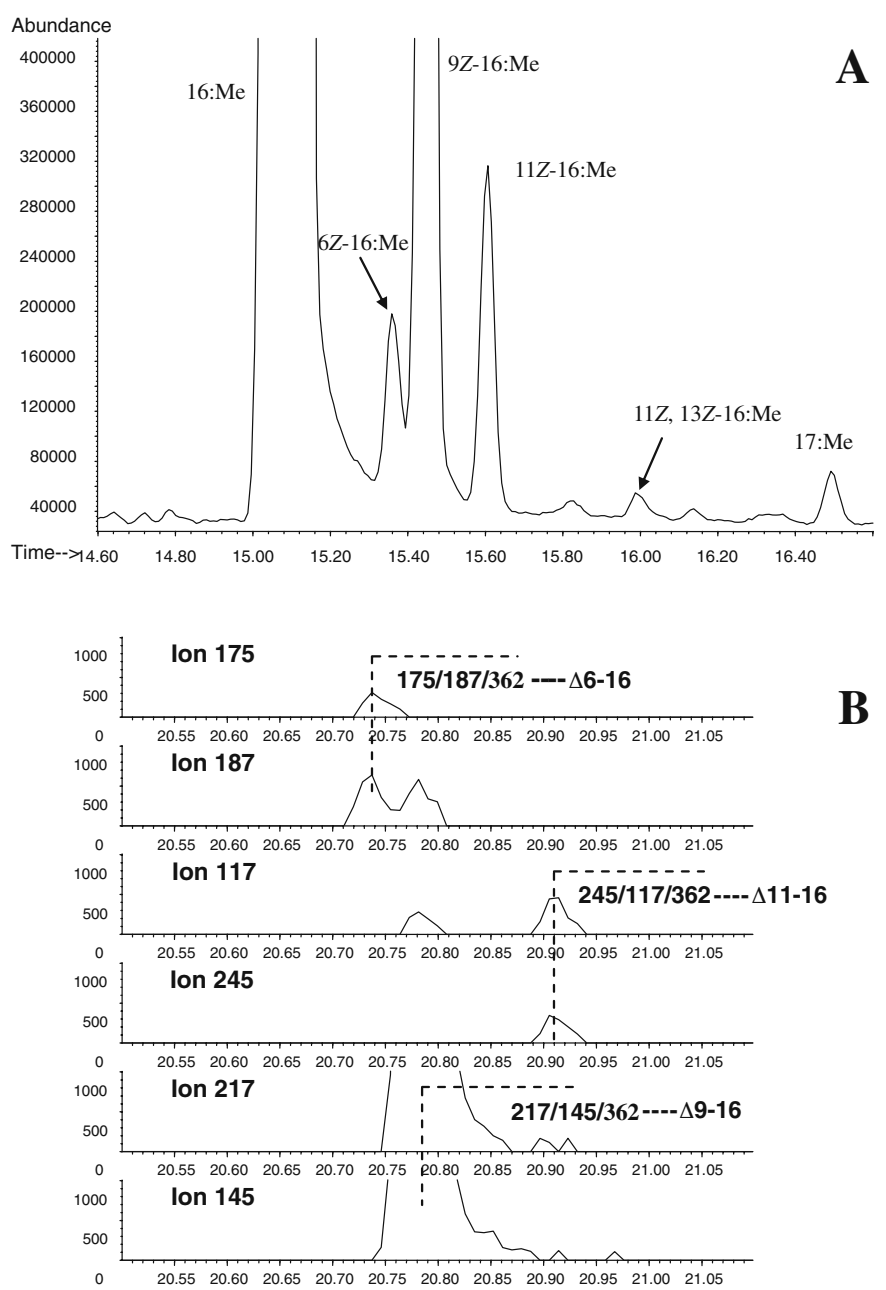

Fig. 3 Representative sections of the total ion chromatograms (TIC) of fatty acid methyl ester DMDS adducts, analyzed on an InnoWax capillary column. a Section of TIC from pheromone gland fatty acid methyl esters. b Selected ion monitoring GC-MS analyses of monounsaturated C16 fatty acid methyl ester DMDS adducts. Double bond positions were identified from the diagnostic ions from cleavage of the $\mathrm{C}-\mathrm{C}$ bond between the two carbons bearing methylthiol groups: $\Delta 6-16,175 / 187 / 362 ; \Delta 9-16,217 / 145 / 362 ; \Delta 11-16,245 / 117 / 362$. c
Labeling Experiment Results Topical application of $\mathrm{D}_{3}-16$ : Acid and $D_{9}-11 Z-16$ :Acid to the pheromone gland of PBAN-injected decapitated females resulted in incorporation of the labeled precursors into 11Z,13Z-16:Ald, with a labeled to unlabelled compounds ratio of $2.7 \pm 2.0 \%(N=4)$ and $44 \pm 23 \%(N=6)$, respectively (Fig. 4a and b). These results demonstrated that both of these acids likely are biosynthetic precursors to $11 Z, 13 Z-16$ :Ald, and that $11 Z$, 13Z-16:Ald synthesis occurs in the pheromone gland.

When $\mathrm{D}_{5}$-linolenic acid was injected into 1-to 2-d-old female pupae, the labeled precursor was incorporated into both the $\mathrm{C}_{23}$ and $\mathrm{C}_{25}$ pentaenes (Fig. 5), with a labeled to
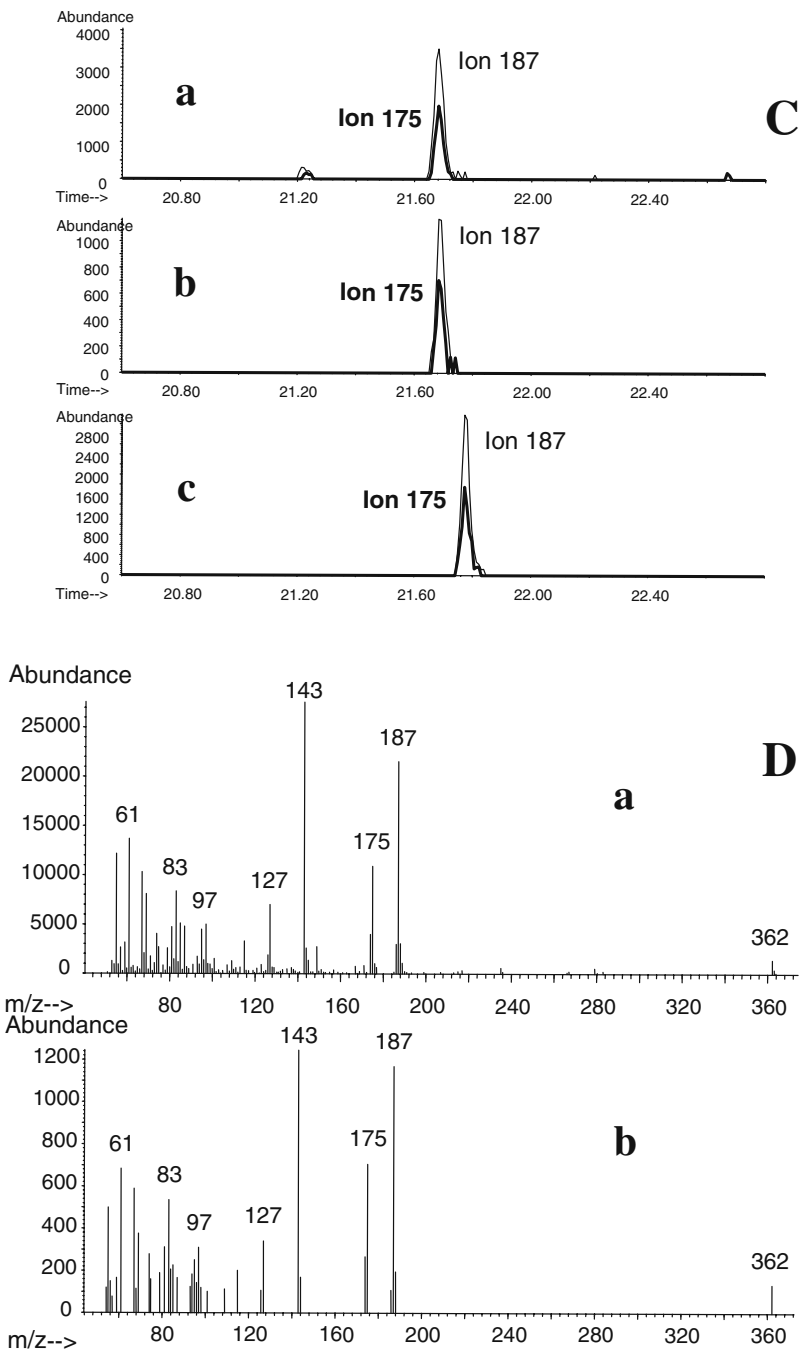

Confirmation of the "cis" configuration in the insect-produced $\Delta 6-16$ monounsaturated fatty acid methyl ester by comparison of the chromatographic retention times of the DMDS adducts, using the diagnostic ions at $m / z 175$ and 187. $a$ : $\Delta 6-16$ :Me DMDS adduct in insect abdomen extract; $b$ : authentic 6Z-16:Me DMDS adduct; $c$ : authentic 6E-16:Me DMDS adduct. d Full scan mass spectrum of the $\Delta$ 6-16 monounsaturated fatty acid methyl ester DMDS adduct from insect abdomen extract $(a)$ and authentic 6Z-16:Me DMDS adduct $(b)$ 

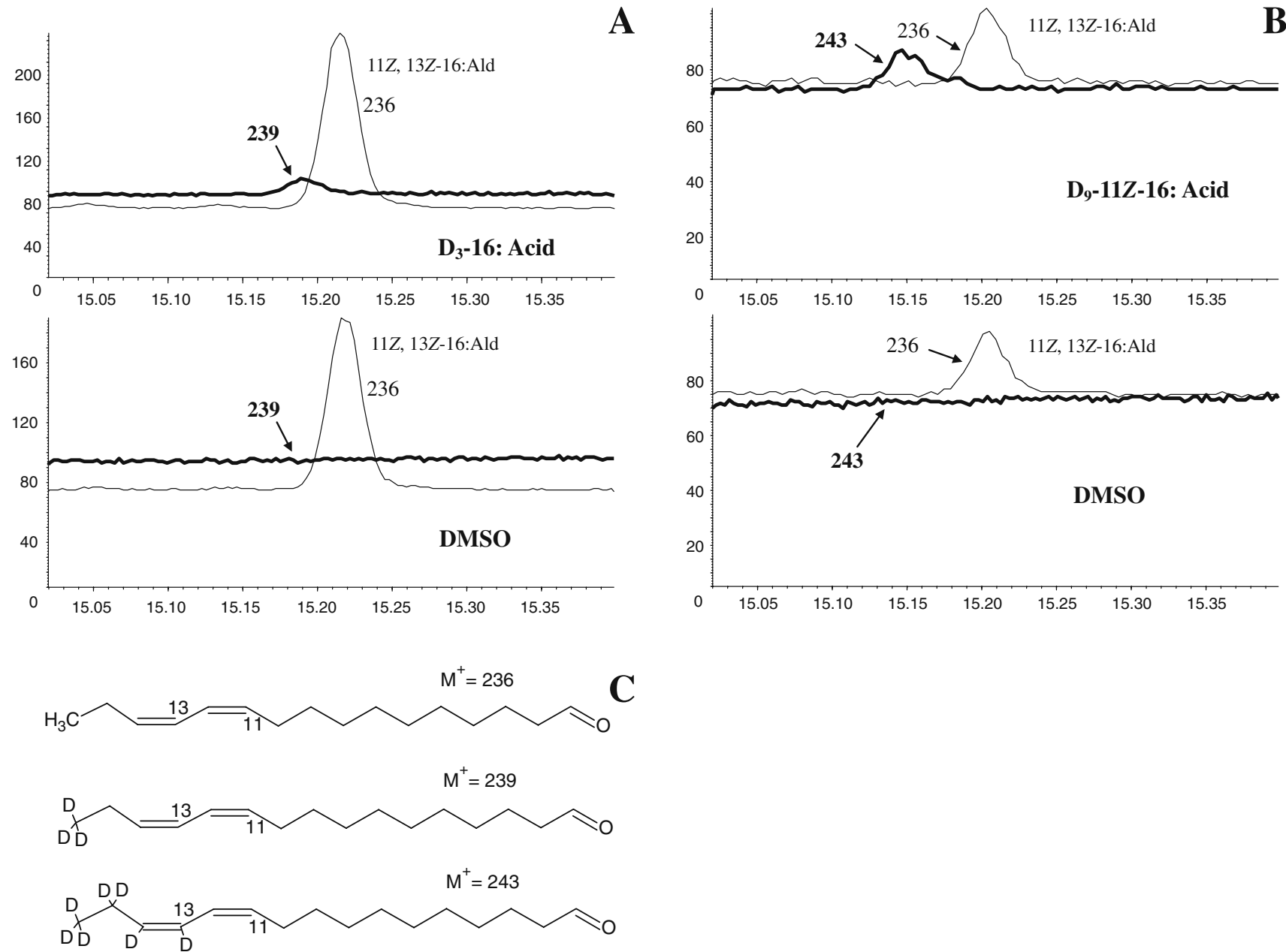

Fig. 4 Selected ion monitoring chromatograms showing incorporation of labeled fatty acid precursors into $11 Z, 13 Z-16$ :Ald, using ions 239 and 243 to monitor $\mathrm{D}_{3}-11 Z, 13 Z-16$ :Ald and $\mathrm{D}_{7}-11 Z, 13 Z-16$ :Ald, respectively. a Deuterium label incorporation into $D_{3}-11 Z, 13 Z-16$ :Ald after topical application of $\mathrm{D}_{3}-16$ :Acid in DMSO onto the pheromone

unlabeled compounds ratio of $4.9 \pm 0.6 \%$ for $\mathrm{C}_{23}$ pentaene in the pheromone gland extracts, a $4.0 \pm 1.2 \%$ ratio in $\mathrm{C}_{23}$ pentaene extracted from the abdominal tissues $(N=3)$, and a $3.6 \pm 0.2 \%$ ratio $(N=3)$ in $\mathrm{C}_{25}$ pentaene extracted from abdominal tissues. Because of the small amount of native $\mathrm{C}_{25}$ pentaene in the pheromone gland, among the labeled samples only one provided clear evidence for incorporation of label $(6.0 \%)$. These results demonstrated that linolenic acid is a precursor for both of the pentaene components, but they do not reveal where the biosynthesis of the pentaenes occurs. However, topical application of $\mathrm{D}_{6}$-linolenic acid to the pheromone gland coupled with PBAN injection, or topical application of $\mathrm{D}_{5}$-linolenic acid onto the pheromone gland without PBAN injection resulted in no detectable incorporation of label into either of the pentaenes. This suggests that the pentaenes are not synthesized in the pheromone gland, and consequently, that they must be gland; b Deuterium label incorporation into $\mathrm{D}_{7}-11 Z, 13 Z$-16:Ald after topical application of $\mathrm{D}_{9}-11 Z-16$ :Acid in DMSO onto the pheromone gland; c diagnostic ions for unlabeled 11Z,13Z-16:Ald, $\mathrm{D}_{3}$-labeled 11Z,13Z-16:Ald and $\mathrm{D}_{7}$-labeled 11Z,13Z-16:Ald

synthesized elsewhere in the abdomen and transported to the pheromone gland for release.

Topical application of $\mathrm{D}_{4}-11 Z, 14 Z, 17 Z-20$ :Acid onto the pheromone gland of intact females without PBAN injection or injection of $\mathrm{D}_{4}-11 Z, 14 Z, 17 Z-20$ :Acid into the abdomens of either pupae or adults also did not result in detectable label incorporation into the pentaenes, indicating that this acid probably is not a precursor to the pheromone.

\section{Discussion}

This is the first example of a lepidopteran insect in which both of the biosynthetic pathways leading to Type I and Type II moth pheromone components, respectively, have been demonstrated. The general steps of the pathways are parallel to those found in moths which use only one or the 

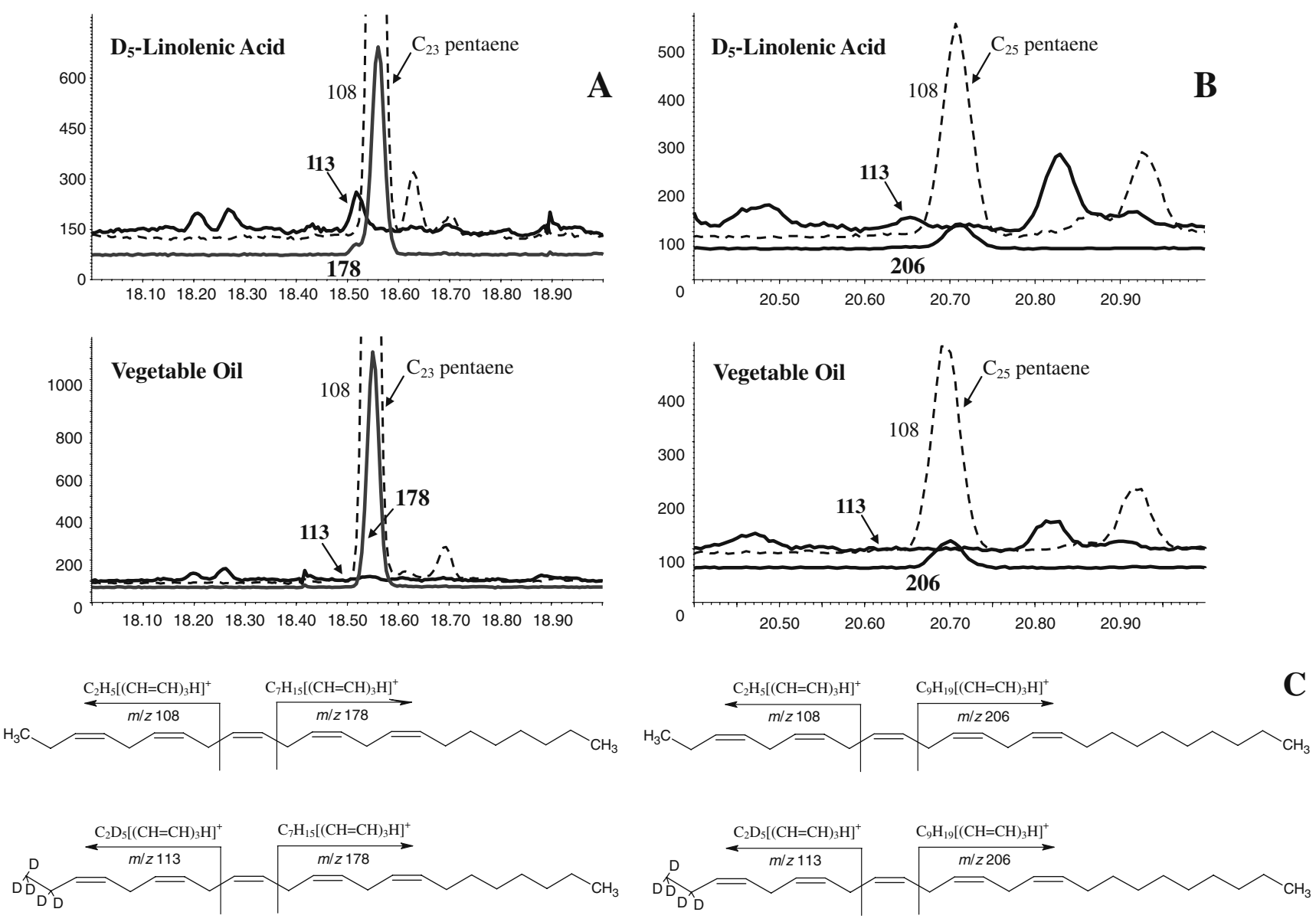

Fig. 5 Selected ion monitoring chromatograms showing incorporation of labeled fatty acid precursors into $3 Z, 6 Z, 9 Z, 12 Z, 15 Z-23: \mathrm{H}$ and $3 Z, 6 Z, 9 Z, 12 Z, 15 Z-25: \mathrm{H}$ after abdominal injection of $\mathrm{D}_{5}$-linolenic acid into $1-2 \mathrm{~d}$ old pupae. a Deuterium label incorporation into $\mathrm{D}_{5^{-}}$ $3 Z, 6 Z, 9 Z, 12 Z, 15 Z-23: \mathrm{H}$; b Deuterium label incorporation into $\mathrm{D}_{5^{-}}$ $3 Z, 6 Z, 9 Z, 12 Z, 15 Z-25: H ;$ c Ions 108 and 178, and ions 108 and 206

were used to monitor unlabeled $3 Z, 6 Z, 9 Z, 12 Z, 15 Z-23: \mathrm{H}$ and $3 Z, 6 Z, 9 Z, 12 Z, 15 Z-25: \mathrm{H}$, respectively. Ions 113 and ion 178 were used to monitor $\mathrm{D}_{5}-3 Z, 6 Z, 9 Z, 12 Z, 15 Z-23: \mathrm{H}$, and ions 113 and 206 were used to monitor $D_{5}-3 Z, 6 Z, 9 Z, 12 Z, 15 Z-25: H$. Because of the small amounts of both native and labeled $3 Z, 6 Z, 9 Z, 12 Z, 15 Z-25: H$, the 206 ion was not detected in labeled $\mathrm{D}_{5}-3 Z, 6 Z, 9 Z, 12 Z, 15 Z-25: \mathrm{H}$

other pathway, with our results suggesting that navel orangeworm females synthesize 11Z,13Z-16:Ald from palmitic acid in the pheromone gland. In contrast, the two pentaenes apparently originate from linolenic acid. The fact that the two pentaenes were found in extracts of the pheromone gland, the abdominal tissue, the abdominal cuticle, and the hemolymph of female navel orangeworm moths (Table 1) are consistent with the hypothesis that the pentaenes are synthesized outside the pheromone gland, possibly in oenocyte cells, and then transferred to the gland through the hemolymph by carrier proteins, as has been shown in other lepidopteran species that produce Type II pheromone components (Jurenka et al. 2003; Wei et al. 2003; Matsuoka et al. 2006; Choi et al. 2007).

As expected, the production of 11Z,13Z-16:Ald in pheromone glands of decapitated females was increased significantly by PBAN injection, whereas the titer of the pentaenes in the gland extracts was not affected by PBAN injection. In addition, the titers of both pentaenes in the gland

extracts were the same regardless of whether the glands were extracted during the photophase or the scotophase (Table 1). Thus, PBAN does not appear to be involved in the production of the pentaenes, similar to what was found with the production of polyenes in the geometrid moth A. selenaria cretacea (Wei et al. 2004) and the arctiid moth U. ornatrix (Choi et al. 2007), and the titer of the pentaenes does not fluctuate with the light-dark cycle.

The fatty acid composition of extracts of pheromone glands and abdominal tissues, coupled with the results showing incorporation of labeled precursors, suggest two distinctly different biosynthetic pathways for the aldehyde and the pentaenes (Figs. 6 and 7). In the pheromone gland, the fatty acid compositions found in the extracts suggested that saturated $\mathrm{C}_{16}$ palmitic acid may be a key substrate, being first desaturated at the 11 position to form 11Z-16: Acid. A second desaturation, possibly mediated by a bifunctional desaturase such as the one known from $T$. pityocampa (Quero et al. 1997; Abad et al. 2007) then may 

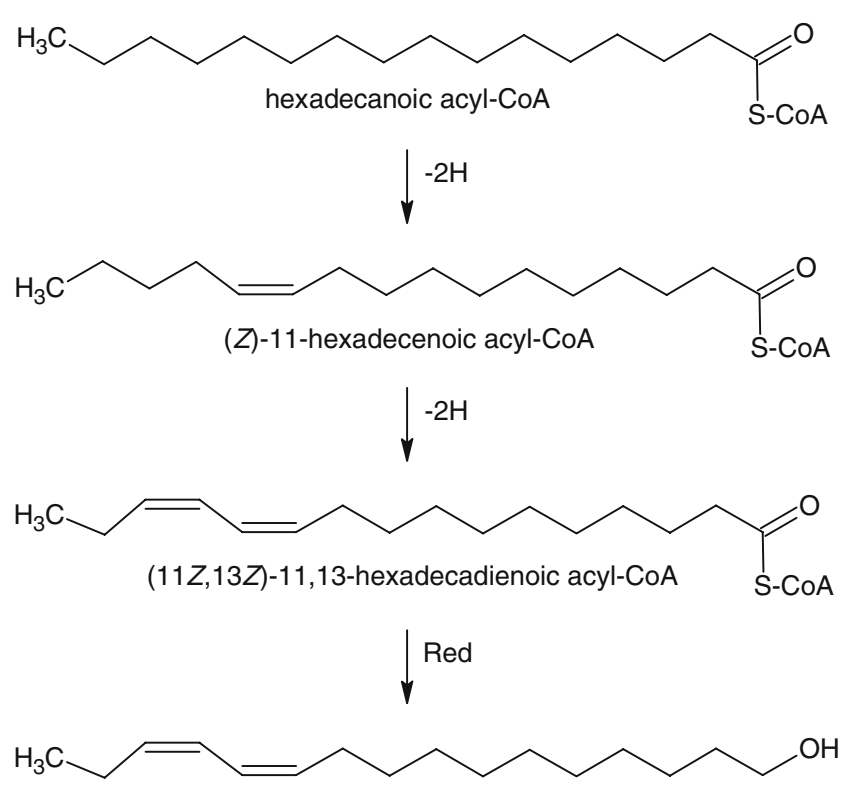

(11Z,13Z)-11,13-hexadecadien-1-ol

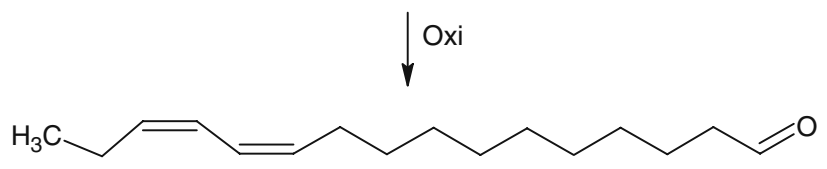

(11Z,13Z)-11,13-hexadecadienal

Fig. 6 Proposed biosynthetic pathway for the Type I 11Z,13Z-16:Ald sex pheromone component produced by female Amyelois transitella. " $-2 \mathrm{H}$ " represents desaturation to form a double bond, "Red" indicates functional group reduction and "Oxi" indicates terminal oxidation form 11Z,13Z-16:Acid, which is subsequently reduced to the corresponding alcohol and finally oxidized to the aldehyde (Fig. 6). The incorporation of deuterium label from saturated $\mathrm{D}_{3}-16$ :Acid and monoenoic $\mathrm{D}_{9}-11 Z-16$ :Acid precursors into $11 Z, 13 Z-16$ :Ald is in agreement with this proposed biosynthetic pathway.

In contrast, our results suggest that the biosynthesis of the two long-chain pentaenes must take place in a markedly different fashion, beginning with different precursors, and likely occurring at a site outside the pheromone gland. The incorporation of deuterium label from labeled linolenic acid into the two pentaenes confirms that linolenic acid can serve as a precursor to these compounds. Furthermore, (5Z,8Z,11Z,14Z,17Z)-icosapentaenoic acid, a likely laterstage intermediate in the biosyntheses of the pentaene hydrocarbons, was found in both abdominal tissue and pheromone gland extracts. Two or three 2-carbon chain extensions of this icosapentaenoic acid would provide the homologous tetracosapentaenoic and hexacosapentaenoic acids, respectively, which would yield the $\mathrm{C}_{23}$ and $\mathrm{C}_{25}$ pentaene hydrocarbons after decarboxylation. These data suggest that the icosapentaenoic acid with all the double bonds in place is a key intermediate in the biosynthesis of the pentaene hydrocarbons. The fact that we could detect no trace of the corresponding $\mathrm{C}_{22}, \mathrm{C}_{24}$, or $\mathrm{C}_{26}$ homologs suggests that this intermediate then undergoes a series of chain extensions and the final decarboxylation with all of the intermediates being continuously bound to the relevant enzymes, so that none of them are available as free entities that would have shown up in the analysis (Fig. 7).

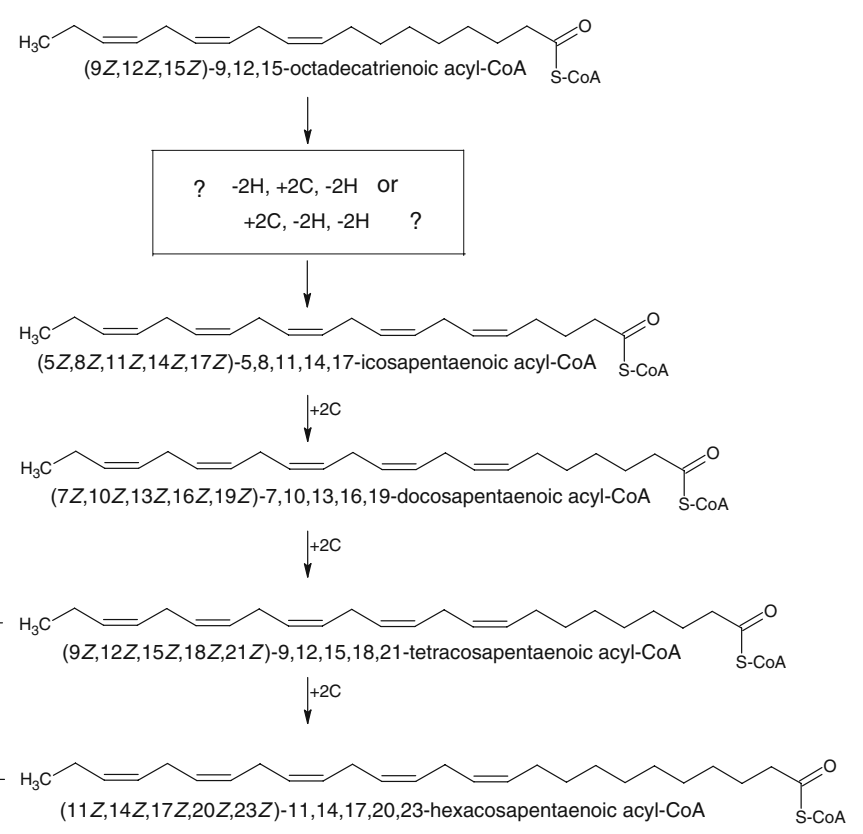

represents one cycle of chain elongation by two carbons, "-COOH" means decarboxylation
Fig. 7 Proposed biosynthetic pathway for the Type II pentaene sex pheromone components produced by female Amyelois transitella. " $-2 \mathrm{H}$ " represents desaturation to form a double bond, " $+2 \mathrm{C}$ " 
The presence of $(5 Z, 8 Z, 11 Z, 14 Z, 17 Z)$-icosapentaenoic acid in the pheromone gland tissue was unexpected, given that most of the total pentaene titer was found in the abdominal tissues (Table 1). However, this acid actually may have been present in the gland extracts only as the result of contamination of the pheromone gland preparations with abdominal tissues, i.e., it is difficult to dissect out pheromone glands that are completely free of surrounding tissues.

Prior studies in other organisms from a broad array of taxa, such as plants, algae, and mammals, suggested a conserved " $\Delta 6$ pathway", i.e., the $\Delta 6$ desaturation of linolenic acid followed by elongation to produce $8 Z, 11 Z$, $14 Z, 17 Z$-icosatetraenoic acid, which is further desaturated at the $\Delta 5$ position to produce the icosapentaenoic acid (Napier 2007). In the zebrafish, a bifunctional $\Delta 6 / \Delta 5$ desaturase has been identified (Hastings et al. 2001), providing a precedent for this proposed pathway. In the present study, small amounts of the unusual (Z)-6-hexadecenoic acid were found in the pheromone gland and the abdomen extracts, which implies that the navel orangeworm may have a corresponding $\Delta 6$ desaturase. The fact that labeled $11 Z, 14 Z, 17 Z$-icosatrienoic acid was not incorporated into the pentaenes also suggests that at least the fourth double bond is introduced before elongation of the 18-carbon chain.

The shift from Type I to Type II pheromone components represents a major evolutionary transition that involves a new site of production, a mechanism for transport and selective uptake of polyunsaturated hydrocarbons into the pheromone gland before release, as well as for the evolution of corresponding receptors in male moths, with matching specificity for the detection of the novel pheromone components. It is difficult to envisage all these changes taking place simultaneously, and it is surprising that there are not more reports of species with mixed/intermediate pheromone systems in, for instance, Geometroidea and Noctuoidea, because these two moth superfamilies have many species that possess either Type I or Type II pheromones. The majority of the species for which mixed pheromones have been reported instead belong to the Pyraloidea, from which no cases of pure Type II (hydrocarbon-type) pheromones have been described (Witzgall et al. 2004; El-Sayed 2008). This suggests that the detailed mechanisms and sites of hydrocarbon biosynthesis may differ between the Geometroidea and Noctuoidea on one hand and the Pyraloidea on the other.

Once the hydrocarbon compounds started being exported to and taken up by the pheromone gland, this opened up the possibility for the modification of these compounds by the gland before release. The production of the epoxide derivatives of polyunsaturated hydrocarbons used by some species in the Geometroidea and Noctuoidea should, thus, represent a more advanced character state. Continued radiation then resulted in epoxidation at different positions, yielding one or the other, or in some cases both of the two possible enantiomers of each epoxide, thus allowing a variety of different semiochemicals to be made from a common precursor.

In vitro molecular cloning and functional analysis of the genes for the specific desaturase, elongase, and decarboxylase enzymes postulated in the biosynthesis of the hydrocarbon pheromone components would be helpful in explaining the entire pathway. Likewise, studies of tissue specific expression and in situ hybridization could clarify where the different reactions actually take place.

Acknowledgments We thank Robbie D. Girling at University of California, Riverside for advice on insect rearing, Erling Jirle at Lund University for laboratory assistance, R. Adlof with USDA-ARS Peoria for providing labeled compounds, and Stefan Schulz of Technische Universität Braunschweig and two anonymous reviewers for helpful suggestions. This work was financially supported by the Swedish Research Council (VR).

Open Access This article is distributed under the terms of the Creative Commons Attribution Noncommercial License which permits any noncommercial use, distribution, and reproduction in any medium, provided the original author(s) and source are credited.

\section{References}

ABAD, J. L., CAMPS, F., and FABRIAS, G. 2007. Substrate-dependent stereochemical course of the (Z)-13-desaturation catalyzed by the processionary moth multifunctional desaturase. J. Am. Chem. Soc. 129:15007-15012.

Ando, T., Ohtani, K., Yamamoto, M., Miyamoto, T., QIn, X. R., and WitJaKsono. 1997. Sex pheromone of Japanese giant looper, Ascotis selenaria cretacea: identification and field tests. J. Chem. Ecol. 23:2413-2423.

Ando, T., InOMATA, S. I., and YAmamoto, M. 2004. Lepidopteran sex pheromones. pp. 51-96, in S. Schulz (ed.). The Chemistry of Pheromones and Other Semiochemicals I: Topics in Current Chemistry, vol. 239. Springer, Berlin, Heidelberg, New York.

Ando, T., KAWAI, T., and MatSUOKA, K. 2008. Epoxyalkenyl sex pheromones produced by female moths in highly evolved groups: biosynthesis and its endocrine regulation. J. Pestic. Sci. 33:17-20.

BJostad, L. B. and Roelofs, W. L. 1984. Sex pheromone biosynthetic precursors in Bombyx mori. Insect Biochem. 14:275-278.

Buser, H. R., Arn, H., Guerin, P., and Rauscher, S. 1983. Determination of double bond position in mono-unsaturated acetates by mass spectrometry of dimethyl disulfide adducts. Anal. Chem. 55:818-822.

Cabrera, A., Eiras, A. E., Gries, G., Gries, R., Urdaneta, N., MirAS, B., BADJI, C., and JAFFE, K. 2001. Sex pheromone of tomato fruit borer, Neolucinodes elegantalis. J. Chem. Ecol. 27:2097-2107.

Carrow, G. M., Calabrese, R. L., and Williams, C. M. 1981. Spontaneous and evoked release of prothoracicotropin from multiple neurohemal organs of the tobacco hornworm. Proc. Natl. Acad. Sci. USA 78:5866-5870.

ChOI, M.-Y., LiM, H., PARK, K. C., AdLOF, R., WANG, S., Zhang, A., and JURENKA, R. 2007. Identification and biosynthetic studies of the hydrocarbon sex pheromone in Utetheisa ornatrix. J. Chem. Ecol. 33:1336-1345. 
Coffelt, J. A., Sower, L. L., and VICK, K. W. 1978. Quantitative analysis of identified compounds in pheromone gland rinses of Plodia interpunctella and Ephestia cautella at different times of day. Environ. Entomol. 7:502-505.

Coffelt, J. A., Vick, K. W., SonNet, P. E., and Doolittle, R. E. 1979. Isolation, identification, and synthesis of a female sex pheromone of the navel orangeworm, Amyelois transitella (Lepidoptera: Pyralidae). J. Chem. Ecol. 5:955-966.

Dunkelblum, E., TAN, S. H., and SilK, P. J. 1985. Double bond location in monounsaturated fatty acids by dimethyl disulfide derivatisation and mass spectrometry: application to analysis of fatty acids in pheromone glands of four Lepidoptera. J. Chem. Ecol. 11:265-277.

EL-SAYED, A. M. 2008. The Pherobase: Database of Insect Pheromones and Semiochemicals. $<\mathrm{http}: / /$ www.pherobase.com>.

Fan, Y., Schal, C., Vargo, E. L., and Bagnères, A.-G. 2004. Characterization of termite lipophorin and its involvement in hydrocarbon transport. J. Insect Physiol. 50:609-620.

Fellenberg, A. J., Johnson, D. W., Poulos, A. and Sharp, P. 1987. Simple mass spectrometric differentiation of the n-3, n-6 and n-9 series of methylene interrupted polyenoic acids. Biomed. Environ. Mass Spectrom. 14:127-130.

Gibb, A. R., Pinese, B., Tenakania, D., Kawi, A. P., Bunn, B., RAMANKUTTY, P., and SUCKLING, D. M. 2007. (Z)-11-Hexadecenal and $(3 Z, 6 Z, 9 Z)$-tricosatriene: sex pheromone components of the red banded mango caterpillar Deanolis sublimbalis. J. Chem. Ecol. 33:579-589.

GIRLING, R. D. and CARDÉ, R. T. 2006. Analysis of the courtship behavior of the navel orangeworm, Amyelois transitella (Walker) (Lepidoptera: Pyralidae), with a commentary on methods for the analysis of sequences of behavioral transitions. J. Insect Behav. 19:498-520.

Goller, S., SzÖcs, G., Francke, W., and Schulz, S. 2007.

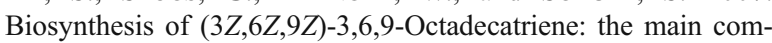
ponent of the pheromone blend of Erannis bajaria. J. Chem. Ecol. 33:1505-1509.

Hastings, N., Agaba, M., Tocher, D. R., Leaver, M. J., Dick, J. R., Sargent, J. R., and Teale, A. J. 2001. A vertebrate fatty acid desaturase with $\Delta 5$ and $\Delta 6$ activities. Proc. Natl. Acad. Sci. USA 98:14304-14309.

JurenKA, R. A. and Roelofs, W. L. 1993. Biosynthesis and endocrine regulation of fatty acid derived sex pheromone in moths, pp. 353-88, in D. W. Stanley-Samuelson, and D. R. Nelson (ed.). Insect Lipids: Chemistry, Biochemistry, and Biology. Univ. Nebr. Press, Lincoln, NB/London.

JURENKA, R. A. and SUBCHEV, M. 2000. Identification of cuticular hydrocarbons and the alkene precursor to the pheromone in hemolymph of the female gypsy moth, Lymantria dispar. Arch. Insect Biochem. Physiol. 43:108-115.

Jurenka, R. A., SubCheV, M., ABAD, J.-L., ChOI, M.-Y., and FABRIÀs, G. 2003. Sex pheromone biosynthetic pathway for disparlure in the gypsy moth, Lymantria dispar. Proc. Natl. Acad. Sci. USA 100:809-914.

KASANG, G., SchneIDER, D., and Beroza, M. 1979. Biosynthesis of the sex pheromone disparlure by olefin-epoxide conversion. Naturwissenschaften 61:130-131.

Kuenen, L. P. S., McElfresh, J. S., and Millar, J. G. 2010. Identification of critical secondary components of the sex pheromone of the navel orangeworm, Amyelois transitella. J. Econ. Entomol. 103: In press.

LANDOLT, P. J. and CURTIS, C. E. 1982. Interspecific sexual attraction between Pyralis farinalis L. and Amyelois transitella (Walker) (Lepidoptera: Pyralidae). J. Kansas Entomol. Soc. 55:248-252.

Leal, W. S., Parra-Pedrazzoli, A. L., Kaissling, K.-E., Morgan, T. I., ZAlom, F. G., PESAK, D. J., Dundulis, E. A., BuRKS, C. S., and HigBeE, B. S. 2005. Unusual pheromone chemistry in the navel orangeworm: novel sex attractants and a behavioral antagonist. Naturwissenschaften 92:139-146.

LÖfstedt, C., Hansson, B. S., Tóth, M., SzÖcs, G., Buda, V., Bengtsson, M., Ryrholm, N., Svensson, M., and Priesner, E. 1994. Pheromone differences between sibling taxa Diachrysia chrysitis (Linnaeus, 1758) and D. tutti (Kostrowicki, 1961) (Lepidoptera: Noctuidae). J. Chem. Ecol. 20:91-109.

MATSUOKA, K., TABUNOKI, H., KaWAi, T., IshiKaWA, S., YAMAMoto, M., SATO, R., and ANDO, T. 2006. Transport of a hydrophobic biosynthetic precursor by lipophorin in the hemolymph of a geometrid female moth which secretes an epoxyalkenyl sex pheromone. Insect Biochem. Mol. Biol. 36:576-583.

Millar, J. G. 2000. Polyene hydrocarbons and epoxides: a second major class of lepidopteran sex attractant pheromones. Annu. Rev. Entomol. 45:575-604.

Millar, J. G., Grant, G. G., Mcelfresh, J. S., StronG, W., Rudolph, C., Stein J. D., and MoreirA, J. A. 2005. (3Z,6Z,9Z,12Z,15Z)Pentacosapentaene, a key pheromone component of the fir coneworm moth, Dioryctria abietivorella. J. Chem. Ecol. 31:1229-1234.

Miller, D. R., Millar, J. G., Mangani, A., Crowe, C. M., and GrANT, G. G. 2010a. (3Z,6Z,9Z,12Z,15Z)-Pentacosapentaene and (Z)-11-hexadecenyl acetate: sex attractant blend for Dioryctria amatella (Lepidoptera: Pyralidae). J. Econ. Entomol. In press.

Miller, D. R., Millar, J. G., Grant, G. G., McDonald, L., and DEBARR, G. L. 2010b. (3Z,6Z,9Z,12Z,15Z)-Pentacosapentaene and $(9 Z, 11 E)$-tetradecadienyl acetate: attractant lure blend for Dioryctria ebeli (Lepidoptera: Pyralidae) in a slash pine seed orchard. J. Entomol. Sci. 45(1):54-57.

Miyamoto, T., Yamamoto, M., Ono, A., Ohtani, K., and Ando, T. 1999. Substrate specificity of the epoxidation reaction in sex pheromone biosynthesis of the Japanese giant looper (Lepidoptera: Geometridae). Insect Biochem. Mol. Biol. 29:63-69.

NAPIER, J. A. 2007. The production of unusual fatty acids in transgenic plants. Annu. Rev. Plant Biol. 58:295-319.

Quero, C., Malo, E. A., Fabrias, G., Camps, F., Lucas, P., Renou, M., and Guerrero, A. 1997. Reinvestigation of female sex pheromone of processionary moth (Thaumetopoea pityocampa): no evidence for minor components. J. Chem. Ecol. 23:713-726.

Rule, G. S. and Roelofs W. L. 1989. Biosynthesis of sex pheromone components from linolenic acid in arctiid moths. Arch. Insect Biochem. Physiol. 12:89-97.

Schal, C., Sevala, V., and Cardé, R. T. 1998a. Novel and highly specific transport of a volatile sex pheromone by hemolymph lipophorin in moths. Naturwissenschaften 85:339-342.

Schal, C., Sevala, V. L., Young, H. P., and Bachmann, J. A. S. 1998b. Sites of synthesis and transport pathways of insect hydrocarbons: cuticle and ovary as target tissues. Amer. Zool. 38:382-393.

Srinivasan, A., Coffelt, J. A., Norman, P., and Williams, B. 1986. Sex pheromone gland of the navel orangeworm, Amyelois transitella (Lepidoptera: Pyralidae) location, bioassay and in vitro maintenance. Florida Entomol. 69:169-174.

Tillman, J. A., Seybold, S. J., JurenKa, R. A., and Blomquist, G. J. 1999. Insect pheromones - an overview of biosynthesis and endocrine regulation. Insect Biochem. Mol. Biol. 29:481-514.

Wei, W., Miyamoto, T., Endo, M., Murakawa, T., Pu, G.-Q., and ANDO, T. 2003. Polyunsaturated hydrocarbons in the hemolymph: biosynthetic precursors of epoxy pheromones of geometrid and arctiid moths. Insect Biochem. Mol. Biol. 33:397-405.

Wei, W., Yamamoto, M., Asato, T., Fujil, T., Pu, G.-Q., and Ando, T. 2004. Selectivity and neuroendocrine regulation of precursor uptake by pheromone glands from hemolymph in geometrid female moths which secrete epoxyalkenyl sex pheromones. Insect Biochem. Mol. Biol. 34:1215-1224.

Witzgall, P., Lindblom, T., Bengtsson, M., and Toth, M. 2004. The Pherolist. (http://www-pherolist.slu.se/pherolist.php). 